DOI: https://doi.org/10.47405/mjssh.v6i1.632

\begin{tabular}{|c|c|}
\hline 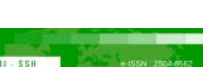 & Malaysian Journal of Social Sciences and Humanities (MJSSH) \\
\hline Malaysian Journal of & Volume 6, Issue 1, January 2021 \\
\hline (Mu-ssH) & e-ISSN : 2504-8562 \\
\hline & $\begin{array}{l}\text { Journal home page: } \\
\text { www.msocialsciences.com }\end{array}$ \\
\hline
\end{tabular}

\title{
Kompetensi Guru dalam Penerapan Kemahiran Berfikir Aras Tinggi dalam Pengajaran Pendidikan Sejarah
}

\author{
Fathizaki Rifin1, Anuar Ahmad1, Norasmah Othman'1 \\ ${ }^{1}$ Fakulti Pendidikan, Universiti Kebangsaan Malaysia (UKM) \\ Correspondence: Fathizaki Rifin (jppfathizaki@gmail.com)
}

\begin{abstract}
Abstrak
Kajian yang dijalankan ini adalah untuk melihat tahap kompetensi guru dalam pelaksanaan Kemahiran Berfikir Aras Tinggi (KBAT) dalam pengajaran pendidikan sejarah dengan melihat perbezaan antara jantina guru dan opsyen mengajar. Kajian tinjauan dengan pendekatan kuantitatif ini melibatkan seramai 100 orang guru Pendidikan Sejarah dalam Daerah Hulu Langat yang dipilih sebagai responden kajian. Borang soal selidik telah digunakan untuk mendapatkan data atau maklumat yang berkaitan dengan kajian. Maklumat data yang diperoleh telah dianalisis menggunakan SPSS Version 22.0 (Statistical for Social Science). Hasil daripada dapatan kajian ini dihuraikan dalam bentuk deskriptif dan inferensi. Ujian $\mathrm{T}$ tidak bersandar telah digunakan untuk melihat tahap kompetensi guru dalam melaksanakan Kemahiran Berfikir Aras Tinggi (KBAT) yang dilihat dari tiga konstruk utama iaitu pengetahuan, kemahiran serta sikap guru. Ujian Manova satu hala pula dijalankan bagi mengenal pasti perbezaan penerapan KBAT dari tiga konstruk utama pedagogi, kurikulum dan pentaksiran dalam pengajaran dan pembelajaran sejarah berdasarkan opsyen mengajar. Dapatan kajian melaporkan bahawa tahap kompetensi guru dalam melaksanakan Kemahiran Berfikir Aras Tinggi (KBAT) dalam pengajaran pendidikan sejarah berada pada aras yang tinggi. Kajian ini juga membuktikan tiada perbezaan yang signifikan terhadap pengajaran guru opsyen Pendidikan Sejarah dan bukan opsyen Pendidikan Sejarah terhadap pelaksanaan KBAT. Ini bermakna guru-guru yang mengajar Sejarah dapat mengamalkan KBAT semasa sesi pengajaran dan pembelajaran Sejarah dengan baik.
\end{abstract}

Kata kunci: Kemahiran Berfikir Aras Tinggi (KBAT), kompetensi guru, Pengajaran dan Pemudahcaraan (PdPC), pedagogi, kurikulum, pentaksiran

\section{Teachers' Competencies in the Implementation of High-Order Thinking Skills in Teaching History}

\begin{abstract}
This study aims to look at the competency level of teachers in the implementation of High-Order Thinking Skills (HOTS) in teaching History by looking at the difference between teacher's gender and teaching options. This survey study with a quantitative approach involved 100 History teachers in Hulu Langat District as the research respondents. Questionnaires have been used to obtain data or information related to the study. The data obtained was analyzed using SPSS Version 22.0 (Statistical For Social Science). The findings of this study are described in descriptive and inferential forms. The independent T-test was used to look at the competency level of teachers in implementing High-Order Thinking Skills (HOTS) seen from three main constructs namely knowledge, skills and teachers' attitude. The one-way Manova test was conducted to identify the differences in the implementation of
\end{abstract}


HOTS from the three main constructs of pedagogy, curriculum and assessment in teaching and learning history based on teaching options. The findings report that the competency level of teachers in implementing High-Order Thinking Skills (HOTS) in teaching History is at a high level. This study also proved that there are no significant differences in teaching among teachers with History options and non History options towards the implementation of HOTS. This means that teachers who teach History can practice HOTS well during teaching and learning sessions.

Keywords: High-Order Thinking Skills (HOTS), teachers' competencies, facilitation and learning $(\mathrm{PdPc})$, pedagogy, curriculum, assessment

\section{Pengenalan}

Pada peringkat pembelajaran yang lebih tinggi, pelajar bukan hanya perlu menguasai Kemahiran Berfikir Aras Rendah (KBAR) tetapi juga perlu menguasai Kemahiran Berfikir Aras Tinggi (KBAT) agar dapat melibatkan diri dalam aktiviti-aktiviti pembelajaran yang kian mencabar (Kusuma et al., 2017). KBAT ditafsirkan sebagai satu bentuk aplikasi pengetahuan, kemahiran dan juga nilai untuk membuat penaakulan dan refleksi (Bahagian Pembangunan Kurikulum, 2014). Menurut Nik Nor Ahmarizam (2015), kepentingan pelaksanaan KBAT turut diamalkan oleh negara maju yang lain seperti England dan Amerika Syarikat bermula tahun 1970-an lagi sebagai persediaan kemenjadian pelajar pada abad ke-21. Dapatan kajian yang dijalankan oleh Saido, Siraj dan Nordin (2015) berkaitan persepsi murid terhadap KBAT oleh tenaga pengajar Institut Pengajian Tinggi di Thailand turut mendapati amalan KBAT sangat penting untuk diterapkan dalam pendidikan.

Kemahiran Berfikir bukanlah lahir secara semula jadi dalam diri manusia tetapi perlu diasah dan diperkembangkan (Puchta, 2012). Transformasi pendidikan oleh Kementerian Pendidikan Malaysia (KPM) telah mengubah dasar bagi meningkatkan lagi kualiti pendidikan khususnya dalam menerapkan KBAT kepada pelajar di sekolah. Kemahiran berfikir perlu dikuasai oleh pelajar agar mampu untuk diaplikasikan dalam dunia pekerjaan kelak. Pendidik merupakan tunjang kepada aspirasi negara untuk membentuk dan juga mendidik murid (Rohizan et al., 2014). Antara elemen-elemen yang terkandung dalam aspirasi pelajar tersebut, kemahiran berfikir dianggap sebagai satu elemen yang sangat penting (Mohd Radzi, 2010). Ciri-ciri pemikiran aras tinggi juga dapat dikategorikan kepada penyelesaian masalah bukan rutin, membina pengetahuan dan melibatkan proses membuat makna yang memerlukan kerja-kerja pemikiran (Yen \& Halili, 2015).

Pengetahuan guru dalam melaksanakan aktiviti KBAT dikenal pasti dapat menyumbang kepada perubahan pendekatan serta kaedah pengajaran guru dalam bilik darjah berdasarkan aspek kurikulum, pedagogi dan juga pentaksiran (Surif et al., 2016). Reka bentuk pendekatan pengajaran pada abad 21 akan lebih menarik sekiranya seiring dengan kemajuan teknologi masa kini (Dembo \& Seli, 2012). Persediaan guru dalam melaksanakan Pengajaran dan Pemudahcaraan (PdPC) yang menekankan kepada KBAT dan pengurusan bilik darjah secara dinamik merupakan salah satu cabaran besar dalam pendidikan abad ke-21 (Susanne, 2014). Kepelbagaian teknik guru dalam mencipta idea baharu, melaksana dan berkomunikasi dengan murid secara berkesan dengan aspek pemikiran kreatif sangat penting dalam proses pengajaran dan (Ahmad \& Majid, 2018).

Sistem pendidikan seharusnya memberikan perhatian yang serius terhadap perbezaan individu dan memberi peluang kepada murid-murid untuk meningkatkan potensi mereka (Mohamad et al., 2012). Secara umumnya, penilaian dan format peperiksaan yang dijalankan di sekolah bermula dari sekolah rendah adalah berasaskan kepada enam aras Kemahiran Berfikir (KB) Taksonomi Bloom (1956) yang terdiri daripada tiga aras rendah iaitu aras pengetahuan, kefahaman dan aplikasi, manakala tiga aras tinggi iaitu analisis, sintesis dan penilaian. 


\section{Pernyataan Masalah Kajian}

Isu dan cabaran guru dalam melaksanakan KBAT antaranya adalah kompetensi guru. Guru sukar untuk membuat perbezaan kepada setiap tahap dalam kemahiran berfikir pelajar serta pengetahuan yang menyeluruh mengenai KBAT (Rajendran, 2000). Pengetahuan guru yang terbatas sepanjang praperkhidmatan dan juga dalam perkhidmatan berkaitan pedagogi yang bersesuaian untuk menerapkan unsur KBAT menyebabkan ketidakupayaan penilaian kepada murid (Zohar, 2013). Kini, semakin banyak pengurusan sekolah yang tidak mampu untuk menguruskan pelaksanaan kemahiran berfikir dikritik dan menjadikan faktor tersebut sebagai punca kepada kemerosotan pencapaian sekolah agak ketinggalan (Rajendran, 2017).

Penilaian dan ujian yang standard pada peringkat kebangsaan dan antarabangsa juga menghalang kepada pengembangan KBAT di sekolah. Hal ini disebabkan guru terikat dengan isu akauntabiliti dalam memberi skor pencapaian (Zohar, 2013). Guru juga perlu mengembangkan kemahiran berfikir murid dengan mengajukan soal jawab yang lebih kritikal sebagai alat bagi tujuan penilaian. Soalan yang dikemukakan kepada murid hanya bertumpu kepada soalan aras rendah yang hanya bergantung kepada ingatan fakta sahaja berbanding soalan aras tinggi yang lebih menekankan kepada proses menganalisis dan berfikir secara mendalam (Tofade, Elsner \& Haines, 2013). Critelli dan Tritapoe (2010) turut menyatakan bahawa soalan-soalan berbentuk terbuka mampu menggalakkan pelajar untuk menaakul dan menggunakan pengetahuan sedia ada mereka.

Kajian yang dijalankan oleh Ong, Hart dan Chen (2016) berkaitan pelaksanaan KBAT turut mendapati guru tidak mampu mengintegrasikan pemikiran yang lebih tinggi, strategi pengajaran yang kurang berkesan dan juga pendekatan yang betul kepada murid. Guru-guru berpendapat bahawa pengajaran dan pembelajaran yang bercirikan KBAT memerlukan persediaan serta perancangan yang rapi (Vijayaletchumy \& Selvam, 2015). Persekitaran pembelajaran juga merupakan isu yang berlaku dalam proses guru untuk menerapkan KBAT kepada pelajar. Susun atur bilik darjah secara tradisional dengan meletakkan murid duduk secara berpasangan dalam satu barisan menghadap guru dan papan putih kekal sehingga ke hari ini. Pengajaran masih lagi berpusatkan guru dan cara tradisional (Nor Hasmaliza \& Zamri, 2016). Ini menyebabkan guru tidak dapat mendorong dan merangsang pemikiran yang lebih tinggi kepada murid disebabkan bilik darjah yang tidak kondusif (Sparapani, 1998).

Seiring dengan perkembangan teknologi yang pesat, proses pembelajaran secara pasif kepada aktif perlu ditekankan seperti murid bekerja dalam kumpulan dan berinteraksi melalui teknologi komputer untuk mencari penyelesaian masalah (Henderson, 2017). Ini bertepatan dengan kajian yang dijalankan oleh Lesser et al. (2013), menyatakan bahawa murid yang terlibat dalam aktiviti yang menyeronokkan akan mengurangkan kebimbangan terhadap kesalahan dan menjadikan mereka berani untuk mencuba serta melibatkan diri dalam aktiviti pengajaran guru.

Pengajaran guru yang tidak sistematik dan tidak berkesinambungan dengan pelajaran sebelumnya telah menyebabkan guru tidak mampu mengaplikasikan KBAT seperti analisis, sintesis, dan juga penilaian dengan sempurna (Musliha, 2010). Hal ini jelas menunjukkan bahawa penguasaan kemahiran berfikir masih berada pada tahap yang rendah dalam kalangan guru dan kepentingan kemahiran berfikir ini dalam pencetusan idea (Yee et al., 2010). Isu dan permasalahan ini perlu ditangani oleh guru-guru secara bersepadu melalui pelbagai cara seperti mengadakan kempen, bengkel strategi, serta kursus KBAT untuk mencorakkan pembangunan pendidikan yang kreatif dalam kalangan murid. Objektif pendidikan yang ingin dicapai dalam inovasi kurikulum memainkan peranan yang penting terhadap kompetensi guru. Rentetan daripada permasalahan di atas, maka satu kajian telah dilaksanakan bagi tiga objektif seperti di bawah:

i. Mengenal pasti tahap kompetensi guru bagi aspek pengetahuan terhadap pelaksanaan KBAT dalam pengajaran pendidikan sejarah.

ii. Mengenal pasti tahap kompetensi guru bagi aspek kemahiran terhadap pelaksanaan KBAT dalam pengajaran pendidikan sejarah.

iii. Mengenal pasti tahap kompetensi guru dari aspek pengetahuan, kemahiran dan juga sikap guru terhadap pelaksanaan KBAT dalam pengajaran pendidikan sejarah berdasarkan opsyen. 


\section{Sorotan Literatur}

\section{Kompetensi}

Kompetensi merujuk kepada kemampuan seseorang dari aspek pengetahuan, sikap dan keterampilan untuk melaksanakan sesuatu kerja dengan cemerlang (Nordin \& Yunus, 2016). Menurut Mulder (2014) kompetensi juga boleh ditakrifkan sebagai satu bentuk prestasi dalam menggunakan kemahiran, pengetahuan dan sikap bagi setiap tindakan profesional dalam sesuatu kepakaran. Langkah KPM dalam menekankan kepada amalan profesional oleh guru di sekolah amat tepat agar tahap kompetensi guru dapat dipertingkatkan. Ini selaras dengan kajian di sekolah-sekolah United Kingdom yang dijalankan oleh Jones dan Harris (2010) apabila mereka mendapati amalan profesional serta kompetensi guru mampu memberikan kesan positif terhadap keseluruhan sistem pendidikan negara. Pendidikan alaf baharu memerlukan guru untuk meningkatkan lagi aspek kompetensi selaras dengan perkembangan teknologi masa kini (Noriati, Boon \& Wong, 2010). Oleh itu, dalam mendepani pembelajaran abad ke -21, guru seharusnya peka dalam penggunaan teknologi ICT dalam literasi pendidikan termasuklah dunia siber, budaya, emosi, ekologi, media dan kewangan (Sulaiman et al., 2013).

Seiring dengan perkembangan teknologi yang pesat, proses pembelajaran secara pasif kepada aktif perlu ditekankan seperti pelajar bekerja dalam kumpulan dan berinteraksi melalui teknologi komputer untuk mencari penyelesaian masalah (Henderson, 2017). Tahap kompetensi guru yang baik akan melahirkan murid yang inovatif dan kreatif (Hasnah \& Jamaludin, 2017). Berdasarkan kajian-kajian yang lepas seperti Lela et al., (2014) serta Mullen dan Schunk (2010) turut menyatakan bahawa amalan Komuniti Pembelajaran Profesional (KPP) dapat meningkatkan kompetensi pengajaran dan pembelajaran guru di dalam bilik darjah.

Kompetensi pengajaran guru juga dikatakan dapat meningkatkan prestasi pelajar melalui penyampaian pengajaran yang jelas dalam bilik darjah seterusnya dapat melonjakkan kualiti sesebuah sekolah. Kementerian Pendidikan Malaysia telah berusaha untuk menambahbaikkan peningkatan kualiti sekolah termasuklah memperkenalkan KPP yang bertujuan menyediakan suatu persekitaran bekerja secara kolaboratif kepada guru supaya dapat mencapai prestasi yang lebih baik untuk murid (Aziah et al., 2015). Kompetensi guru dapat ditingkatkan melalui peer coaching, kolaborasi serta latihan personal. Peranan rakan sejawat juga boleh membantu rakan mereka yang lemah dalam PdPC agar keupayaan pendidik dapat ditingkatkan (Fletcher \& Maher, 2015; Louis \& Seashore, 2014).

\section{Kemahiran Berfikir Aras Tinggi (KBAT)}

KBAT merupakan satu bentuk keupayaan untuk mengaplikasikan pengetahuan, kemahiran dan nilai dalam membuat penaakulan serta refleksi bagi menyelesaikan masalah, membuat keputusan, berinovasi dan berupaya mencipta sesuatu (Lembaga Peperiksaan Malaysia, 2013). KBAT juga merupakan salah satu agenda penting pemerkasaan taraf pendidikan di Malaysia. KBAT melibatkan kemahiran yang kritis, logik, meta kognitif dan kreatif. Pemikiran ini terhasil apabila seseorang itu berhadapan dengan masalah yang jarang ditemui, berusaha untuk menyelesaikan masalah yang sukar dan semasa berada di alam dilema (King et al., 2013). Rajendran (2010) pula menyatakan bahawa KBAT merupakan aras yang paling tinggi di dalam hierarki proses kognitif seseorang. Dalam konteks kajian yang telah dijalankan, pengkaji hanya merujuk kepada empat aras KBAT yang tertinggi iaitu menganalisis, mensintesiskan dan juga menilai berpandukan Model Taksonomi Bloom.

Kesediaan guru menjadi titik tolak kepada kejayaan pelaksanaan KBAT kerana guru merupakan individu penting atau pelaksana kepada kurikulum yang digubal (Mohamad Nurul et.al., 2017). Guru perlu menguasai dan menyesuaikan diri dari aspek pengetahuan, pelaksanaan, kesediaan serta sikap mereka terhadap transformasi yang dilaksanakan dalam kurikulum pendidikan (Siti Nurliyana, 2015). Kemahiran berfikir guru merupakan model penting yang berperanan dalam melaksanakan pengajaran KBAT dengan pengetahuan yang mantap (Orhan \& Yasemin Karsantik, 2016). 
Strategi pengajaran yang digunakan dan tingkah laku guru dapat menggalakkan kemahiran berfikir pelajar. Penerapan KBAT dapat meningkatkan daya pengamatan seseorang pelajar seterusnya dapat memproses maklumat baharu untuk menerbitkan pelbagai alternatif, idea, tindakan, penyelesaian dan rekaan untuk penyelesaian sesuatu masalah (Ismail et al., 2015). Kajian yang dijalankan oleh Hasmaliza (2016), menyatakan bahawa pengetahuan guru berkaitan KBAT masih pada tahap yang sederhana. Sebelum penerapan KBAT ini ditekankan dalam bilik darjah, guru perlu mengetahui secara mendalam kaedah-kaedah penilaian kemahiran berfikir serta mewujudkan suasana bilik darjah yang mampu merangsang pelajar untuk berfikir di luar kotak. Dalam kajian kompetensi guru menerapkan KBAT dalam pengajaran pendidikan sejarah ini, elemen KBAT dilihat dari aspek pedagogi, kurikulum dan pentaksiran.

Pedagogi melibatkan perkembangan kognitif dan afektif pelajar. Pedagogi dimaksudkan sebagai satu proses pengajaran yang melibatkan pengetahuan dan kemahiran berkaitan sesuatu disiplin ilmu (SirajBlatchford, et al. 2003). Menurut Ngasiman (2014) pedagogi merupakan perkataan Yunani yang membawa maksud kecekapan guru untuk melakukan proses pembelajaran yang berkesan.

Kurikulum pula difahami sebagai bentuk pengaturan mengenai tujuan, isi, dan bahan pelajaran serta cara yang digunakan sebagai pedoman penyelenggaraan kegiatan pembelajaran bagi mencapai tujuan pendidikan tertentu (Sukmadinata, 2008). Kurikulum merupakan satu bentuk rencana yang memberi pedoman atau pegangan dalam proses kegiatan belajar mengajar. Proses untuk menggalakkan murid berfikir seharusnya bermula daripada guru terlebih dahulu untuk mengetahui fakta dan konsep bagi sesuatu topik atau tema dalam sukatan mata pelajaran (Sukiman et al., 2012). Dalam konteks kajian, pedagogi dan kurikulum berfokus kepada kaedah pengajaran guru serta pendekatan yang digunakan dalam mengaplikasikan KBAT.

Pentaksiran di sekolah terdiri daripada pentaksiran formatif dan pentaksiran sumatif yang dirancang, dibina, ditadbir, diperiksa, direkodkan dan dilaporkan oleh guru sekolah yang berkenaan (Lembaga Peperiksaan Malaysia (LPM), 2013). Pentaksiran formatif merupakan satu bentuk ujian formal atau tidak formal untuk mengesan tahap penguasaan dan kemajuan murid di dalam kelas. Pentaksiran sumatif merupakan satu jenis ujian formal untuk mengesan tahap pencapaian dalam sesuatu tahap persekolahan dilakukan pada hujung pembelajaran dengan membuat pertimbangan dan penilaian prestasi pelajar dalam pembelajaran. Dalam konteks kajian ini, pentaksiran pembelajaran merujuk kepada penilaian pembelajaran ke atas murid yang digunakan oleh guru melalui instrumen pentaksiran.

Menurut Nurulhuda (2014) pemilihan pendekatan pengajaran guru yang betul mempengaruhi sikap dan pemikiran pelajar pada aras tinggi. Ini juga menyokong dapatan daripada Barathimalar (2014) yang mendapati bahawa guru menyedari kepentingan pengajaran KBAT yang mampu mempengaruhi sikap berfikir murid. Justeru, kompetensi guru sangat berkait dengan amalan guru bagi penerapan KBAT dalam bilik darjah. Secara keseluruhannya, kajian lepas yang telah dijalankan ini menunjukkan bahawa tahap penguasaan guru dalam melaksanakan KBAT semasa pengajaran dan pembelajaran adalah tinggi. Kajian yang lepas telah menunjukkan hasil dapatan yang menunjukkan KBAT tidak dapat dilaksanakan sepenuhnya disebabkan oleh faktor dalaman guru yang masih kurang pengalaman dalam mengendalikan KBAT.

\section{Metod Kajian}

Reka bentuk kajian kuantitatif berbentuk deskriptif dijalankan dalam kajian ini dengan menggunakan kaedah tinjauan di Sekolah Kebangsaan yang terpilih dalam daerah Hulu Langat, Selangor. Kajian ini melibatkan 100 orang guru Pendidikan Sejarah sebagai responden yang berkhidmat di 25 buah Sekolah Kebangsaan dalam daerah Hulu Langat, Selangor. Rasional pemilihan daerah Hulu Langat sebagai lokasi kajian adalah kerana pengkaji melihat jumlah sekolah yang paling banyak di negeri Selangor adalah dalam daerah ini. Jumlah guru daripada 65 buah Sekolah Kebangsaan daripada 89 buah Sekolah Rendah secara keseluruhan dalam daerah Hulu Langat dapat mewakili dapatan kajian yang dilaksanakan (Panduan Pengurusan Pejabat Pendidikan Daerah Hulu Langat, 2018). Guru-guru 
ini telah dipilih secara rawak mudah. Penentuan saiz sampel hanya melibatkan seramai 100 orang guru dengan jumlah populasi seramai 200 orang (Jadual Penentuan Krejcie \& Morgan 1970). Pertimbangan penyelidik dalam menentukan populasi kajian perlu dilaksanakan agar dapatan diperoleh secara sistematik dan teratur. Sebanyak 150 borang melalui Microsoft Forms dihantar menggunakan telegram dan sebanyak 100 responden yang menjawab dengan lengkap sahaja dijadikan sebagai sampel.

Instrumen kajian yang digunakan bagi mendapatkan maklumat mengenai kompetensi guru dalam menerapkan KBAT dalam pengajaran pendidikan sejarah ialah soal selidik. Soal selidik dalam kajian ini dibahagikan kepada tiga bahagian. Bahagian A iaitu demografi responden terdiri daripada tiga item: jantina, pengalaman mengajar dan opsyen mengajar guru. Bahagian B (30 item) pula berkaitan kompetensi amalan guru dalam melaksanakan KBAT dalam pengajaran pendidikan sejarah dari aspek pengetahuan, kemahiran dan sikap. Item-item dalam bahagian ini telah diadaptasi dan diubahsuai berpandukan kajian Mohammad Rusdi (2017) dan Mohd Fauzi et al. (2017). Bahagian C (30 item) pula berkaitan dengan penerapan KBAT dari aspek kurikulum, pedagogi dan pentaksiran. Item-item dalam bahagian ini pula telah diadaptasi dan diubahsuai berpandukan kajian Zunaida (2015) dan Siti Hasnah et al., (2015). Skala likert lima point digunakan di dalam instrumen ini iaitu skala 1 hingga 5 (5=Sangat Setuju hingga 1=Sangat Tidak Setuju).

Pengesahan pembinaan soal selidik ini dirujuk kepada tiga orang pakar dalam bidang Sains Sosial dan Sejarah bagi menentukan kesesuaian konstruk dan item yang diguna pakai adalah sesuai dengan kajian. Pakar tersebut merupakan pensyarah di Jabatan Kajian Sosial, Institut Pendidikan Guru Malaysia. Daripada 30 item soalan yang diberikan kepada pakar, 26 item telah dipersetujui dengan nilai $87 \%$. Setelah mendapat pengesahan pakar, terdapat cadangan dan perubahan item-item yang disesuaikan mengikut konstruk dan ada sebahagian item dan konstruk diabaikan dan disusun semula item-item mengikut kesesuaian konstruk maka proses untuk kajian rintis dilakukan. Tahap kesahan kajian dilaksanakan melibatkan kepada inventori soalan yang perlu diperiksa dan disemak terlebih dahulu (Niu, 2010). Secara keseluruhannya, instrumen kajian ini mempunyai nilai kesahan 0.85 iaitu melebihi 0.80 (Davis, 1992). Ini bermakna instrumen mempunyai nilai kesahan yang baik.

Bagi nilai kebolehpercayaan pula, nilai Cronbach Alpha bagi setiap subkonstruk kompetensi sejarah bagi aspek pengetahuan adalah 0.870 , aspek kemahiran 0.900 manakala bagi aspek sikap 0.855 . Nilai indeks pekali kebolehpercayaan 0.7 adalah boleh diterima (Nunally, 1978). Oleh itu, item-item yang mengukur subkonstruk mempunyai ketekalan dalaman yang tinggi dan baik.

Maklumat data yang diperoleh telah dianalisis menggunakan SPSS Version 22.0 (Statistical For Social Science). Analisis deskriptif untuk mendapatkan min dan sisihan piawai. Bagi analisis infrensi pula, Ujian Manova satu hala digunakan bagi mengenal pasti perbezaan aspek-aspek kompetensi guru dan penerapan KBAT berdasarkan opsyen mengajar guru Sejarah.

Jadual 1: Interpretasi skor min

\begin{tabular}{cc}
\hline Skor Min & Interpretasi \\
\hline $1.00-2.33$ & Rendah \\
$2.34-3.67$ & Sederhana \\
$3.68-5.00$ & Tinggi \\
\hline
\end{tabular}

Sumber: Pallant (2010)

\section{Hasil Kajian}

Secara keseluruhannya, kajian ini berkaitan tahap kompetensi guru dalam penerapan KBAT dalam pengajaran pendidikan sejarah. Dapatan yang dilaporkan adalah maklum balas yang diperoleh daripada 100 orang responden. 


\section{Mengenal pasti tahap kompetensi guru bagi aspek pengetahuan terhadap pelaksanaan KBAT dalam pengajaran pendidikan sejarah}

Jadual 2 menunjukkan dapatan bagi objektif kajian pertama. Berpandukan data yang diperoleh, tahap kompetensi guru bagi aspek pengetahuan terhadap pelaksanaan KBAT dalam pengajaran pendidikan sejarah mengikut pandangan responden adalah berada pada tahap yang tinggi (min 3.85, s.p 0.42). Manakala, interpretasi skor min ini merujuk kepada Pallant (2010) dalam Jadual 1.

Data yang ditunjukkan bagi setiap penyataan dalam jadual menggambarkan peratus persetujuan responden untuk setiap item cenderung kepada skala Setuju dan Sangat Setuju. Sebagai contoh, bagi item B7 'Saya tahu cara penggunaan soalan dan penyoalan yang dapat meningkatkan KBAT murid' mendapati peratus persetujuan sebanyak $80.2 \%$ (81). Dapatan ini mempunyai sedikit persamaan dengan kajian Norfariza (2018) terhadap 275 orang guru di Sekolah Kebangsaan daerah Sepang, Selangor. Dapatan kajian yang diperoleh turut menunjukkan peratusan 61.1\% (168) guru mengetahui penggunaan soalan dan penyoalan yang bersesuaian dalam pelaksanaan KBAT. Menurut M. Mojibur (2010) kemahiran penyoalan guru dalam pengajaran perlu menggunakan soalan-soalan yang membimbing para pelajar. Guru juga perlu mengembangkan potensi berfikir murid, memberikan idea yang jelas, serta dapat menggerakkan daya imaginasi murid. Dapatan ini berbeza dengan kajian Zarina (2016) yang menyatakan kecenderungan guru hanya menggunakan teknik penyoalan pada aras rendah bagi penerapan KBAT dalam pengajaran.

Kecenderungan guru menggunakan teknik penyoalan beraras rendah dalam pengajaran mereka juga merupakan isu pedagogi guru dalam penerapan KBAT (Sharifah et al., 2012). Data yang ditunjukkan bagi item B2 'Saya mengetahui kandungan sukatan pelajaran Sejarah yang mengandungi elemen $K B A T$ ' pula mendapati peratus tidak setuju sebanyak 4.0\% (4). Dapatan ini disokong oleh kajian Sharifah et al. (2012) menyatakan pengetahuan guru yang kurang terhadap elemen KBAT menyukarkan guru untuk mengaplikasikannya dalam proses PdPC. Guru sewajarnya menguasai kandungan dan ilmu pengetahuan berkaitan konsep KBAT secara mendalam agar keberkesanan pengajaran pendidikan Sejarah dapat diamalkan kepada murid Zamri (2014).

Jadual 2: Tahap kompetensi guru bagi aspek pengetahuan

\begin{tabular}{|c|c|c|c|c|c|c|}
\hline Item & Pernyataan & STS & TS & $\mathbf{S}$ & ST & SS \\
\hline B1 & $\begin{array}{l}\text { Saya mengetahui cara } \\
\text { pelaksanaan KBAT di dalam } \\
\text { bilik darjah }\end{array}$ & $\begin{array}{l}0 \% \\
(0)\end{array}$ & $\begin{array}{l}1.0 \% \\
(1)\end{array}$ & $\begin{array}{l}16.8 \% \\
(17)\end{array}$ & $\begin{array}{l}69.3 \% \\
(70)\end{array}$ & $\begin{array}{l}12.9 \% \\
(13)\end{array}$ \\
\hline B2 & $\begin{array}{l}\text { Saya mengetahui kandungan } \\
\text { sukatan pelajaran Sejarah } \\
\text { yang mengandungi elemen } \\
\text { KBAT }\end{array}$ & $\begin{array}{l}0 \% \\
(0)\end{array}$ & $\begin{array}{l}4.0 \% \\
(4)\end{array}$ & $\begin{array}{l}30.7 \% \\
(31)\end{array}$ & $\begin{array}{l}55.4 \% \\
(56)\end{array}$ & $\begin{array}{l}9.9 \% \\
(10)\end{array}$ \\
\hline B3 & $\begin{array}{l}\text { Saya mengetahui aras } \\
\text { kognitif Kemahiran Berfikir } \\
\text { Aras Rendah dalam } \\
\text { Taksonomi Bloom }\end{array}$ & $\begin{array}{l}0 \% \\
(0)\end{array}$ & $\begin{array}{l}2.0 \% \\
(2)\end{array}$ & $\begin{array}{l}28.7 \% \\
(29)\end{array}$ & $\begin{array}{l}50.5 \% \\
(51)\end{array}$ & $\begin{array}{l}18.8 \% \\
(19)\end{array}$ \\
\hline B4 & $\begin{array}{l}\text { Saya mengetahui aras } \\
\text { kognitif KBAT dalam } \\
\text { Taksonomi Bloom }\end{array}$ & $\begin{array}{l}0 \% \\
(0)\end{array}$ & $\begin{array}{l}3.0 \% \\
(3)\end{array}$ & $\begin{array}{l}29.7 \% \\
(30)\end{array}$ & $\begin{array}{l}52.5 \% \\
(53)\end{array}$ & $\begin{array}{l}14.9 \% \\
(15)\end{array}$ \\
\hline B5 & $\begin{array}{l}\text { Saya tahu pelbagai yang } \\
\text { bersesuaian untuk digunakan } \\
\text { untuk menerapkan KBAT } \\
\text { dalam pengajaran dan } \\
\text { pembelajaran }\end{array}$ & $\begin{array}{l}0 \% \\
(0)\end{array}$ & $\begin{array}{l}1.0 \% \\
(1)\end{array}$ & $\begin{array}{l}27.7 \% \\
(28)\end{array}$ & $\begin{array}{l}60.4 \% \\
(61)\end{array}$ & $\begin{array}{l}10.9 \% \\
(11)\end{array}$ \\
\hline B6 & $\begin{array}{l}\text { Saya mengetahui bahan } \\
\text { bantu mengajar yang } \\
\text { bersesuaian yang boleh } \\
\text { digunakan untuk }\end{array}$ & $\begin{array}{l}0 \% \\
(0)\end{array}$ & $\begin{array}{l}1.0 \% \\
(1)\end{array}$ & $\begin{array}{l}24.8 \% \\
(25)\end{array}$ & $\begin{array}{l}63.4 \% \\
(64)\end{array}$ & $\begin{array}{l}10.9 \% \\
(11)\end{array}$ \\
\hline
\end{tabular}




\begin{tabular}{|c|c|c|c|c|c|c|}
\hline & meningkatkan KBAT murid & & & & & \\
\hline B7 & $\begin{array}{l}\text { Saya tahu cara menggunakan } \\
\text { peta i-Think dalam } \\
\text { pengajaran dan } \\
\text { pembelajaran untuk } \\
\text { meningkatkan KBAT }\end{array}$ & $\begin{array}{l}0 \% \\
(0)\end{array}$ & $\begin{array}{l}0 \% \\
(0)\end{array}$ & $\begin{array}{l}16.8 \% \\
(17)\end{array}$ & $\begin{array}{l}64.4 \% \\
(65)\end{array}$ & $\begin{array}{l}18.8 \% \\
(19)\end{array}$ \\
\hline B8 & $\begin{array}{l}\text { Saya tahu menerapkan } \\
\text { KBAT dalam isi kandungan } \\
\text { pelajaran berdasarkan } \\
\text { kepada tahap kognitif dan } \\
\text { kebolehan murid }\end{array}$ & $\begin{array}{l}0 \% \\
(0)\end{array}$ & $\begin{array}{l}1.0 \% \\
\text { (1) }\end{array}$ & $\begin{array}{l}27.7 \% \\
(28)\end{array}$ & $\begin{array}{l}63.4 \% \\
(64)\end{array}$ & $\begin{array}{l}7.9 \% \\
(8)\end{array}$ \\
\hline B9 & $\begin{array}{l}\text { Saya tahu menerapkan } \\
\text { KBAT melalui isi } \\
\text { kandungan pelajaran dalam } \\
\text { masa yang ditetapkan }\end{array}$ & $\begin{array}{l}0 \% \\
(0)\end{array}$ & $\begin{array}{l}1.0 \% \\
\text { (1) }\end{array}$ & $\begin{array}{l}26.7 \% \\
(27)\end{array}$ & $\begin{array}{l}64.4 \% \\
(65)\end{array}$ & $\begin{array}{l}7.9 \% \\
(8)\end{array}$ \\
\hline B10 & $\begin{array}{l}\text { Saya tahu cara penggunaan } \\
\text { soalan dan penyoalan yang } \\
\text { dapat meningkatkan KBAT } \\
\text { murid }\end{array}$ & $\begin{array}{l}0 \% \\
(0)\end{array}$ & $\begin{array}{l}0 \% \\
(0)\end{array}$ & $\begin{array}{l}11.9 \% \\
(12)\end{array}$ & $\begin{array}{l}80.2 \% \\
(81)\end{array}$ & $\begin{array}{l}7.9 \% \\
(8)\end{array}$ \\
\hline & $\begin{array}{l}\text { Purata Min } \\
\text { Purata Sisihan Piawai } \\
\text { Tahap Interpretasi }\end{array}$ & & $\begin{array}{l}3.85 \\
0.42 \\
\text { Tinggi }\end{array}$ & & & \\
\hline
\end{tabular}

$$
\begin{aligned}
& \text { STS = Sangat Tidak Setuju } \\
& \text { TS = Tidak Setuju } \\
& \text { S = Sederhana } \\
& \text { ST = Setuju } \\
& \text { SS = Sangat Setuju }
\end{aligned}
$$

\section{Mengenal pasti tahap kompetensi guru bagi aspek kemahiran terhadap pelaksanaan KBAT dalam pengajaran pendidikan sejarah}

Jadual 3 membincangkan dapatan untuk persoalan kajian kedua. Dapatan diperoleh berkaitan tahap kompetensi guru bagi aspek kemahiran terhadap pelaksanaan KBAT dalam pengajaran pendidikan sejarah oleh responden berada pada tahap yang tinggi (min 3.77, s.p 0.40). Ini menunjukkan kompetensi guru Pendidikan Sejarah yang mengajar subjek Sejarah dapat mengaplikasikan kemahiran tertinggi KBAT sepanjang sesi pengajaran. Dapatan ini selaras dengan kajian Hover, Hicks dan Dack (2016) menunjukkan tahap kemahiran guru merupakan domain yang mempengaruhi keberkesanan serta pelaksanaan sesuatu kaedah pengajaran dan pembelajaran di dalam kelas.

Data yang diperoleh menunjukkan setiap penyataan dalam jadual menggambarkan peratus persetujuan responden bagi setiap item cenderung kepada skala Setuju dan Sangat Setuju. Sebagai contoh, item C5 'Saya dapat menyusun atur pengajaran secara lebih sistematik' dengan peratus persetujuan sebanyak 72.3\% (73) telah menjawab 'Setuju' dan 8.9\% (9) menjawab 'Sangat Setuju'. Dapatan ini tidak selari dengan kajian Zulkifli (2015) yang mendapati penerapan KBAT tidak dilaksanakan secara konsisten oleh guru dalam PdPC disebabkan kekangan masa untuk mengejar silibus pelajaran. Bagi item C4 'Saya menggunakan kata kerja KBAT (mencipta) dalam aktiviti pengajaran dan pembelajaran menunjukkan peratus sederhana dengan nilai 38.6\% (39). Dapatan ini menunjukkan cabaran guru bagi menerapkan sepenuhnya aras tertinggi dalam KBAT. Dapatan kajian ini mempunyai persamaan dengan kajian Abdul Halim (2016) yang menyatakan cabaran guru untuk menggalakkan murid berfikir secara bercapah berkaitan isu atau topik dalam pelajaran. Justeru, kompetensi guru bagi aspek kemahiran dalam KBAT sangat diperlukan bagi mengelakkan masalah murid kurang berminat untuk belajar dan sebagai bekal untuk murid mendepani alam pekerjaan kelak setelah tamat persekolahan (Nasyimah \& Zamri Mahomad, 2016). 
DOI: https://doi.org/10.47405/mjssh.v6i1.632

Penerapan KBAT dalam penulisan karangan argumentatif amat mencabar menurut kedua-dua peserta kajian memandangkan berlakunya ledakan teknologi maklumat dan komunikasi (TMK) yang mempengaruhi pelaksanaan PdPc di bilik darjah.

Jadual 3: Tahap kompetensi guru bagi aspek kemahiran

\begin{tabular}{|c|c|c|c|c|c|c|}
\hline Item & Pernyataan & STS & TS & S & ST & SS \\
\hline $\mathbf{C 1}$ & $\begin{array}{l}\text { Saya menggunakan kata } \\
\text { kerja KBAT (aplikasi) } \\
\text { dalam aktiviti pengajaran } \\
\text { dan pembelajaran }\end{array}$ & $\begin{array}{l}0 \% \\
(0)\end{array}$ & $\begin{array}{l}2.0 \% \\
(2)\end{array}$ & $\begin{array}{l}29.7 \% \\
(30)\end{array}$ & $\begin{array}{l}63.4 \% \\
(64)\end{array}$ & $\begin{array}{l}5.0 \% \\
(5)\end{array}$ \\
\hline $\mathrm{C} 2$ & $\begin{array}{l}\text { Saya menggunakan kata } \\
\text { kerja KBAT (analisis) } \\
\text { dalam aktiviti pengajaran } \\
\text { dan pembelajaran }\end{array}$ & $\begin{array}{l}0 \% \\
(0)\end{array}$ & $\begin{array}{l}2.0 \% \\
(2)\end{array}$ & $\begin{array}{l}38.6 \% \\
(39)\end{array}$ & $\begin{array}{l}55.4 \% \\
(56)\end{array}$ & $\begin{array}{l}4.0 \% \\
(4)\end{array}$ \\
\hline $\mathbf{C 3}$ & $\begin{array}{l}\text { Saya menggunakan kata } \\
\text { kerja KBAT (menilai) } \\
\text { dalam aktiviti pengajaran } \\
\text { dan pembelajaran }\end{array}$ & $\begin{array}{l}0 \% \\
(0)\end{array}$ & $\begin{array}{l}2.0 \% \\
(2)\end{array}$ & $\begin{array}{l}33.7 \% \\
(34)\end{array}$ & $\begin{array}{l}60.4 \% \\
(61)\end{array}$ & $\begin{array}{l}4.0 \% \\
(4)\end{array}$ \\
\hline $\mathrm{C4}$ & $\begin{array}{l}\text { Saya menggunakan kata } \\
\text { kerja KBAT (mencipta) } \\
\text { dalam aktiviti pengajaran } \\
\text { dan pembelajaran }\end{array}$ & $\begin{array}{l}0 \% \\
(0)\end{array}$ & $\begin{array}{l}2.0 \% \\
(2)\end{array}$ & $\begin{array}{l}38.6 \% \\
(39)\end{array}$ & $\begin{array}{l}54.5 \% \\
(55)\end{array}$ & $\begin{array}{l}5.0 \% \\
(5)\end{array}$ \\
\hline C5 & $\begin{array}{l}\text { Saya melibatkan murid } \\
\text { secara aktif dalam proses } \\
\text { PdPC }\end{array}$ & $\begin{array}{l}0 \% \\
(0)\end{array}$ & (0) & $\begin{array}{l}9.9 \% \\
(10)\end{array}$ & $\begin{array}{l}70.3 \% \\
(71)\end{array}$ & $\begin{array}{l}19.8 \% \\
(20)\end{array}$ \\
\hline C6 & $\begin{array}{l}\text { Saya dapat menjalankan } \\
\text { aktiviti PdPC dalam masa } \\
\text { yang ditetapkan dengan } \\
\text { menerapkan elemen KBAT }\end{array}$ & $\begin{array}{l}0 \% \\
(0)\end{array}$ & $\begin{array}{l}1.0 \% \\
(1)\end{array}$ & $\begin{array}{l}25.7 \% \\
(26)\end{array}$ & $\begin{array}{l}65.3 \% \\
(66)\end{array}$ & $\begin{array}{l}7.9 \% \\
(8)\end{array}$ \\
\hline C7 & $\begin{array}{l}\text { Saya menerapkan KBAT } \\
\text { dalam pengajaran dan } \\
\text { pembelajaran mengikut } \\
\text { potensi murid }\end{array}$ & $\begin{array}{l}0 \% \\
(0)\end{array}$ & $\begin{array}{l}1.0 \% \\
(1)\end{array}$ & $\begin{array}{l}25.7 \% \\
(26)\end{array}$ & $\begin{array}{l}64.4 \% \\
(65)\end{array}$ & $\begin{array}{l}8.9 \% \\
(9)\end{array}$ \\
\hline C8 & $\begin{array}{l}\text { Saya dapat menyusun atur } \\
\text { pengajaran secara lebih } \\
\text { sistematik }\end{array}$ & $\begin{array}{l}0 \% \\
(0)\end{array}$ & $\begin{array}{l}0 \% \\
(0)\end{array}$ & $\begin{array}{l}18.8 \% \\
(19)\end{array}$ & $\begin{array}{l}72.3 \% \\
(73)\end{array}$ & $\begin{array}{l}8.9 \% \\
(9)\end{array}$ \\
\hline C9 & $\begin{array}{l}\text { Saya dapat merancang } \\
\text { pengajaran yang mencabar } \\
\text { minda murid }\end{array}$ & $\begin{array}{l}0 \% \\
(0)\end{array}$ & $\begin{array}{l}1.0 \% \\
(1)\end{array}$ & $\begin{array}{l}33.7 \% \\
(34)\end{array}$ & $\begin{array}{l}59.4 \% \\
(60)\end{array}$ & $\begin{array}{l}5.9 \% \\
(6)\end{array}$ \\
\hline $\mathrm{C10}$ & $\begin{array}{l}\text { Saya dapat menentukan } \\
\text { objektif pengajaran dan } \\
\text { pembelajaran untuk } \\
\text { melaksanakan proses } \\
\text { pengajaran berasaskan } \\
\text { KBAT } \\
\text { Purata Min } \\
\text { Purata Sisihan Piawai } \\
\text { Tahap Interpretasi } \\
\end{array}$ & $\begin{array}{l}0 \% \\
(0)\end{array}$ & $\begin{array}{l}3.77 \\
0.40 \\
\text { Tinggi }\end{array}$ & $\begin{array}{l}24.8 \% \\
(25)\end{array}$ & $\begin{array}{l}65.3 \% \\
(66)\end{array}$ & $\begin{array}{l}8.9 \% \\
(9)\end{array}$ \\
\hline
\end{tabular}

STS = Sangat Tidak Setuju

TS $=$ Tidak Setuju

$\mathrm{S}=$ Sederhana

ST $=$ Setuju

SS = Sangat Setuju 


\section{Mengenal pasti tahap kompetensi guru dari aspek pengetahuan, kemahiran dan juga sikap guru terhadap pelaksanaan KBAT dalam pengajaran pendidikan sejarah berdasarkanopsyen.}

Berdasarkan Jadual 4 menunjukkan terdapat perbezaan yang signifikan kompetensi guru Sejarah bagi aspek pengetahuan $(\mathrm{F}=12.207, \mathrm{p}=0.001)$ berdasarkan opsyen. Guru sejarah $(\mathrm{min}=4.05$, sisihan piawai $=0.41)$ mempunyai min yang lebih tinggi berbanding guru bukan sejarah $(\min =3.75$, sisihan piawai $=0.39$ ). Dapatan turut menunjukkan terdapat perbezaan yang signifikan kompetensi guru bagi aspek kemahiran $(\mathrm{F}=6.808,0.010)$ berdasarkan opsyen. Guru sejarah $(\min =3.92$, sisihan piawai $=$ $0.45)$ mempunyai min yang lebih tinggi berbanding guru bukan sejarah $(\min =3.70$, sisihan piawai $=$ $0.35)$. Namun demikian, tidak terdapat perbezaan yang signifikan kompetensi guru bagi aspek sikap ( $\mathrm{F}$ $=1.608, \mathrm{p}=0.208$ ) berdasarkan opsyen.

Jadual 4: ANOVA Satu Hala Perbezaan Kompetensi Guru Berdasarkan Opsyen

\begin{tabular}{|c|c|c|c|c|c|c|c|c|c|c|}
\hline & & $\mathbf{N}$ & Min & $\begin{array}{l}\text { Sisiha } \\
\text { n } \\
\text { Piawa }\end{array}$ & & $\begin{array}{l}\text { Jumlah } \\
\text { Kuasa } \\
\text { Dua }\end{array}$ & df & $\begin{array}{l}\text { Min } \\
\text { Kuasa } \\
\text { Dua }\end{array}$ & $\mathbf{F}$ & Sig. \\
\hline \multirow[t]{3}{*}{ Pengetahuan } & Sejarah & 32 & 4.056 & 0.413 & $\begin{array}{l}\text { Antara } \\
\text { Kumpulan }\end{array}$ & 1.964 & 1 & 1.964 & 12.207 & 0.001 \\
\hline & $\begin{array}{l}\text { Bukan } \\
\text { Sejarah }\end{array}$ & 69 & 3.756 & 0.395 & $\begin{array}{l}\text { Dalam } \\
\text { Kumpulan }\end{array}$ & 15.928 & 99 & 0.161 & & \\
\hline & Total & 101 & 3.851 & 0.422 & Keseluruhan & 17.892 & 100 & & & \\
\hline \multirow[t]{3}{*}{ Kemahiran } & Sejarah & 32 & 3.921 & 0.452 & $\begin{array}{l}\text { Antara } \\
\text { Kumpulan }\end{array}$ & 1.034 & 1 & 1.034 & 6.808 & 0.010 \\
\hline & $\begin{array}{l}\text { Bukan } \\
\text { Sejarah }\end{array}$ & 69 & 3.704 & 0.357 & $\begin{array}{l}\text { Dalam } \\
\text { Kumpulan }\end{array}$ & 15.043 & 99 & 0.152 & & \\
\hline & Total & 101 & 3.773 & 0.400 & Keseluruhan & 16.078 & 100 & & & \\
\hline \multirow[t]{3}{*}{ Sikap } & Sejarah & 32 & 3.865 & 0.293 & $\begin{array}{l}\text { Antara } \\
\text { Kumpulan }\end{array}$ & 0.135 & 1 & 0.135 & 1.608 & 0.208 \\
\hline & $\begin{array}{l}\text { Bukan } \\
\text { Sejarah }\end{array}$ & 69 & 3.787 & 0.288 & $\begin{array}{l}\text { Dalam } \\
\text { Kumpulan }\end{array}$ & 8.330 & 99 & 0.084 & & \\
\hline & Total & 101 & 3.811 & 0.290 & Keseluruhan & 8.466 & 100 & & & \\
\hline
\end{tabular}

\section{Kesimpulan}

Melihat kepada kepentingan kompetensi guru Pendidikan Sejarah dalam menerapkan KBAT, pelbagai implikasi dan kesan terhadap sekolah, kurikulum, pengajaran dan pembelajaran serta pelajar khususnya dalam subjek Sejarah. Kompetensi guru dikenal pasti dapat memberikan impak yang besar kepada kecemerlangan murid. Guru yang kompeten serta mempunyai komitmen yang tinggi akan mampu membuat penilaian yang adil kepada murid, memupuk minat yang tinggi kepada murid. Kajian ini telah menjelaskan kepentingan kompetensi guru Sejarah terhadap pelaksanaan KBAT dalam konteks pengetahuan dan kemahiran dalam pengajaran dan pembelajaran sejarah. Tahap kompetensi guru yang tinggi merupakan aset kepada sekolah dan pihak Kementerian Pendidikan Malaysia kerana untuk mewarnai murid-murid dengan ilmu fungsional yang mantap bagi merealisasikan kecemerlangan dalam pendidikan. Amatlah diharapkan agar hasil kajian ini dapat dijadikan panduan ke arah penambahbaikan kualiti guru melalui pembangunan profesionalisme berterusan bagi menghasilkan kecemerlangan dalam menjalankan tugas utama mengajar di dalam bilik darjah, membimbing dan mengenal pasti keperluan pelajar serta memupuk semangat belajar yang tinggi ke dalam jiwa pelajar agar sentiasa berusaha mencapai kecemerlangan.

Bagi memastikan guru-guru mudah untuk melaksanakan serta memantapkan lagi penyampaian dan pentaksiran KBAT yang berkesan di semua sekolah, kursus-kursus berkaitan KBAT sewajarnya diberikan perhatian yang serius oleh pihak JPN dan KPM. Guru Pendidikan Sejarah perlu diberikan sokongan dan pendedahan yang sewajarnya dalam melaksanakan intervensi serta inovasi yang 
bersesuaian merangkumi bahan rujukan, pendekatan, pemilihan strategi pengajaran dalam melaksanakan KBAT. Guru pendidikan Sejarah juga perlu diberikan bahan sokongan seperti modul KBAT sebagai panduan dan rujukan dalam pengajaran. Bahagian Pembangunan Kurikulum (BPK) perlu membuat penambahbaikan terhadap modul dan buku panduan KBAT agar guru-guru yang berkemahiran dapat mengaplikasikannya kepada murid.

\section{Rujukan}

Anida Sarudin, Dahlia Janan, Zulkifli Osman dan Ahmad Khair. (2017). Linguistics Approach as Teacher Pedagogy in Inculcating Cognitive Aspects of Preschool Children. Journal of Applied Environmental and Biological Sciences ,7(1S), 1-11.

Aziah Ismail, Yen, L. H., \& Kanesan, A. G. (2015). Komuniti Pembelajaran Profesional Dan Efikasi Kendiri Guru Sekolah Menengah Di Pulau Pinang. Jurnal Kepimpinan Pendidikan, 2(1), 1- 12

Critelli, A. \& Tritapoe, B. 2010. Effective questioning techniques to increase class participation. $e$ Journal of Student Research, 2(1).

Fletcher, D., \& Maher, J. (2015). Toward a Competency-Based Understanding of the Training and Development of Applied Sport Psychologists. (July). https://doi.org/10.1037/a0031976

Henderson, P. (2017). Computer science, problem solving, and discrete mathematics, (January), 333342. https://doi.org/10.1090/dimacs/036/28

Hover, S.V., Hicks, D., \& Dack, H. (2016). From Source to Evidence? Teachers' Use of Historical Sources in Their Classrooms. The Social studies, 107(6), 209-217.

Jones, M., \& Harris, A. (2010). Professional Learning Communities and System Improvement. Sage Journals, 13(2), 172-181. https://doi.org/10.1177/1365480210376487

Lesser, L.M., Wall, A.A., Carver, R.H., Pearl, D.K., Martin, N. \& Kuiper, S. 2013. Using fun in the statistics classroom: An exploratory study of college instructors' hesitations and motivations. Journal of Statistics Education, 21(1).

Louis, \& Seashore, K. (2014). The Role of Professional Learning Communities In International Education. https://doi.org/10.1007/978-94-010-0375-9

M. Mojibur Rahman. 2010. Teaching oral communication skills: A task based approach. ESP

Mohamad Nurul Azmi, M., N., Nurzatulshima, K., Umi Kalthom, A. M. \& Mohd Hazwan, M. P. (2017). Penerapan Kemahiran Berfikir Aras Tinggi (KBAT) dalam Kurikulum Reka Bentuk dan Teknologi (RBT) Sekolah Rendah. International Journal of Education and Training, 3(2), 1-7. World Issue, 1(27): 1-11. http://www.esp.world.info [25 Disember 2014]

Mohammad Rusdi Ab Majid. 2017. Pengetahuan Teknologi Pedagogi Kandungan dan Kreativiti Pengajaran Dalam Kalangan Guru Bahasa Arab di Malaysia. Tesis Dr. Falsafah, Universiti Malaya.

Mohd Fauzi, Abdul Razaq, A.A.S. 2017. Teachers' Competencies in Teaching and Learning History. Open Journal of Social Sciences 05(08): 220-228

Musliha Salma Mohd Radzi. 2010. Aplikasi Kemahiran Berfikir Aras Tinggi Melalui Pembelajaran Berasaskan Masalah. Skudai: Penerbit Universiti Teknologi Malaysia

Ngasiman, N (2014). Kesan Kaedah Pembelajaran Koperatif Terhadap Pencapaian Pelajar Dalam Mata Pelajaran Matematik. Universiti Tun Hussien Onn Malaysia. Tesis Sarjana.

Nor Hasmaliza Hasan \& Zamri Mahamod. (2016). Persepsi Guru Bahasa Melayu Sekolah Menengah terhadap Kemahiran Berfikir Aras Tinggi. Jurnal Pendidikan Bahasa Melayu- JPBM, 6(2), 7890.

Orhan Akinoglu \& Yasemin Karsantik. (2016). Pre-services teachers opinions on teaching thinking skills. International Journal of Instruction, 9-2.

Pallant, J. (2010). SPSS Survival manual: a step by step guide to data analysis using SPSS (Fourth edition). Berkshire, UK: McGraw Hill.

Saido, G. M., Siraj, S., Nordin, A. B. B., \& Al_Amedy, O. S. (2018). Higher order thinking skills among secondary school students in science learning. MOJES: Malaysian Online Journal of Educational Sciences, 3(3), 13-20.

Sharifah Nor, P., Nor Adibah, G., Mohd Mahzan, T. \& Aliza, A. (2012). Keperihatinan Guru Bahasa melayu dalam Melaksanakan kemahiran Berfikir Secara kritis dan Kreatif. Jurnal Pendidikan Bahasa Melayu, 2, 19-31. 
DOI: https://doi.org/10.47405/mjssh.v6i1.632

Volk, M., Cotič, M., Zajc, M., \& Starcic, A. I. (2017). Tablet-based cross-curricular maths vs. traditional maths classroom practice for higher-order learning outcomes. Computers \& Education, $114,1-23$ 